\title{
Quantification of Cannabinoids in Cannabis Oil Using GC/MS: Method Development, Validation, and Application to Commercially Available Preparations in Argentina
}

\section{두)(1) $(8)$}

Authors

Nicolás Fernández, Laura Jorgelina Carreras, Rafael Antonio Larcher, Adriana Silvia Ridolfi, Patricia Noemí Quiroga(D

\begin{abstract}
Affiliation
Facultad de Farmacia y Bioquímica, Universidad de Buenos Aires, Cátedra de Toxicología y Química Legal, Laboratorio de asesoramiento toxicológico analítico (CENATOXA), Ciudad Autónoma de Buenos Aires (CABA), Buenos Aires, Argentina
\end{abstract}

\section{Key words}

cannabis oil, Cannabis sativa L., Cannabaceae, cannabinoids, gas chromatography, mass spectrometry, Method Validation Natural Products Analysis

$$
\begin{array}{ll}
\text { received } & 19.12 .2019 \\
\text { revised } & 11.03 .2020 \\
\text { accepted } & 05.04 .2020
\end{array}
$$

\section{Bibliography}

DOI https://doi.org/10.1055/a-1155-6613

Planta Med Int Open 2020; 7: e81-e87

(c) Georg Thieme Verlag KG Stuttgart · New York

ISSN 2509-9264

\section{Correspondence}

Patricia Noemi Quiroga

Facultad de Farmacia y Bioquímica, Universidad de Buenos Aires, Cátedra de Toxicología y Química Legal CENATOXA, Junín 956 7mo piso (C1113AAD), Ciudad Autónoma de Buenos Aires (CABA)

Buenos Aires

Argentina

Tel.: + 541152874757 , Fax: + 541152874759

arpquiroga@ffyb.uba.ar

\section{ABSTRACT}

The medicinal use of cannabis oil is increasing all over the world. Few analytical methods for the quantification of cannabinoids have been validated using internationally accredited guidelines. This work describes the development and validation of a selective and sensitive gas chromatography-mass spectrometry method for the qualitative analysis of the main can- nabinoids, namely cannabidiolic acid, tetrahydrocannabinolic acid, cannabigerol, and cannabichromene as well as quantitative determination of cannabidiol, $\Delta^{9}$-tetrahydrocannabinol, and cannabinol, present in cannabis oils. The method was fully validated according to Food and Drug Administration and International Conference on Harmonization guidelines. A linear range of $0.1-30 \mu \mathrm{g} / \mathrm{mL}$ was obtained for CBD and $\Delta^{9}-\mathrm{THC}$ and $0.034-11.7 \mu \mathrm{g} / \mathrm{mL}$ for $\mathrm{CBN}$, presenting determination coefficients above 0.99 . The lower limits of quantification ranged from 0.034 to $0.1 \mu \mathrm{g} / \mathrm{mL}$. The intra- and inter-day precision, calculated in terms of relative standard deviation, were 3.9-13.8 and 4.7-14.1\%, respectively. Extraction efficiency at lower limits of quantification was 95-103\%. Verification of method validity was performed with authentic cannabis oil samples. To our knowledge, this is the first method available in Argentina, validated according to international guidelines, for quantification of CBD, $\Delta^{9}$-THC, and CBN in cannabis oil. The primary application of this method is to differentiate between cannabis oils with high or low content of $\Delta^{9}-\mathrm{THC}, \mathrm{CBD}$, or mixed $\Delta^{9}$-THC/CBD. This is of fundamental importance for the patient and so that the physicians can carry out a suitable therapy.

$\begin{array}{ll}\text { ABBREVIATIONS } \\ \text { CBC } & \text { cannabichromene } \\ \text { CBD } & \text { cannabidiol } \\ \text { CBDA } & \text { cannabidiolic acid } \\ \text { CBG } & \text { cannabigerol } \\ \text { CBN } & \text { cannabinol } \\ \text { FDA } & \text { Food and Drug Administration } \\ \text { GC-MS } & \text { gas chromatography-mass spectrometry } \\ \text { ISTD } & \text { internal standard } \\ \text { ICH } & \text { International Conference on Harmonization } \\ \text { LLOQ } & \text { lower limits of quantification } \\ \text { MSTFA } & \text { N-methyl-N-trimethylsilyltrifluoroacetamide } \\ \text { THCA } & \text { tetrahydrocannabinolic acid } \\ \triangle^{9} \text {-THC } & \text { trans- } \Delta^{9} \text {-tetrahydrocannabinol } \\ \text { WADA } & \text { World Anti-Doping Agency }\end{array}$




\section{Introduction}

The medicinal use of Cannabis sativa L. (Cannabaceae) products is increasing all over the world. The most common therapeutic indications of cannabis and cannabinoids are for the treatment of pediatric resistant epilepsy, chronic noncancer pain, multiple sclerosis, dyskinesias of Huntington's and Parkinson's diseases, and tics of Tourette syndrome [1].

Cannabis oil extracts are prepared from dried Cannabis sativa $L$. inflorescences and incorporated in common edible oils (e. g., olive or sunflower) or even obtained using these oils as extraction media.

Cannabinoids are terpene phenolic compounds typical of the cannabis plant. $\Delta^{9}$-THC is the most psychoactive constituent in cannabis. It has many diverse pharmacological effects with therapeutic value in the treatment of different medical conditions [2-5].

Other non-psychotropic cannabinoids, mainly CBD and CBN, are increasingly researched, showing partially distinctive effects [6-11]. Thus, quantification of these cannabinoids is also important to understanding the pharmacological properties of cannabis oil. $\triangle^{9}$-THC and CBD are present in the plant as THCA and CBDA, respectively $[12,13]$. Decarboxylation is temperature-dependent $[14,15]$, and preheating of cannabis samples has been recommended to potentiate the final cannabis oil extract $[16,17]$.

Medical cannabis oils generally possess high levels of the therapeutic CBD and lower levels (generally less than $0.3 \%$ ) of the psychotropic $\Delta^{9}$-THC. The FDA has issued warning letters to firms that market unapproved new drugs that allegedly contain CBD. As part of these actions, the FDA has determined the cannabinoid content of some cannabis oil products (not approved by the FDA), and many were found to contain levels of CBD that are very different from the label claim [18].

In Argentina, cannabis and its derivatives are schedule IV-controlled substances (prohibited use) [19], but new regulations have allowed production for medical purposes through licensed producers [20]. Production of commercial cannabis oil in Argentina must take place in a facility using good manufacturing practices, and products must be tested for the presence and content of $\Delta^{9}$-THC and $C B D$, using validated analytical methods.

Several methods, based on GC [21-24] or LC [24-26] have been published for the determination of $\triangle^{9}$-THC, CBD, and other cannabinoids in cannabis oil. GC, one of the most used techniques for the quantitative analysis of cannabinoids in plant materials, has been in use for a long time. The high temperature of the injection port transforms the acid cannabinoids into the neutral cannabinoids. Since the cannabis oils contain the acidic and neutral forms, a derivatization step is required to prevent the decarboxylation $[27,28]$, and trimethylsilyl derivatives have been shown to be suitable for analysis $[28,29]$. Thereby, the value of total cannabinoids can be measured by determining the acid and neutral form separately. In contrast to GC, LC-based techniques allow the direct analysis of cannabinoid (neutral and acid) in the extracted sample.

The main goal of the present work is the development, optimization, and validation of a method with a simple derivatization coupled to GC-MS for the determination of $\triangle^{9}$-THC, CBD, and CBN in cannabis oil.

The GC-MS validated method, according to FDA [30] and ICH [31] guidelines, has proven to be very accurate, highly reproducible, and sensitive to determine the target cannabinoids, with only
$10 \mu \mathrm{L}$ of sample tested. In addition, the method was successfully applied to the quantitative analysis of 10 different cannabis oils. The application of this method to differentiate between cannabis oils with high or low content of $\Delta^{9}$-THC, CBD, or mixed $\Delta^{9}$-THC/CBD will provide physicians with essential information so that they can carry out a suitable therapy with patient's pathology.

\section{Results and Discussion}

An accurate and robust analytical method has been developed for the quantification of 3 cannabinoids relevant to the health and safety of cannabis oil users. This process was optimized for dilution solvent and sonication time. Dilution solvents had been selected according to the existing literature $[23,25,32,33]$ and to the physical-chemical properties of the studied analytes. The solvents evaluated were methanol, ethanol, diethyl ether, and petroleum ether. To evaluate the effect of different sonication times, the samples were sonicated at various times $(5,10,20$, and $30 \mathrm{~min})$. These experiments were performed in triplicate using cannabis oil, and the relative peak areas obtained for each cannabinoid were compared to establish the best dilution solvent and sonication time. An initial prescreening (methanol and 5 min sonication time) of cannabinoids was made in full scan mode. Mass spectrometric identification criteria were according to the WADA $[34,35]$. The cannabinoids identified were $\triangle^{9}$-THC, CBD, CBN, CBC, CBG, THCA, and CBDA.

The statistical analysis of these data indicated that dilution solvent was the most significant factor ( $\vee$ Fig. 1). Regarding diethyl ether, the recoveries obtained for $\triangle^{9}$-THC, CBN, CBC, THCA, and CBDA were significantly greater when compared to using methanol: [F (1.4) $=10.85, p<0.05]$, $[F(1.4)=36.74, p<0.05]$, [F $(1.4)=8.37, p<0.05][F(1.4)=102.94, p<0.05]$, and $[F$ $(1.4)=107.49, p<0.05]$, respectively. Subsequently, the recoveries obtained with diethyl ether for $\triangle^{9}$-THC, CBN, CBC, THCA, and CBDA were significantly greater when compared to using ethanol: $[F(1.4)=10.53, p<0.05],[F(1.4)=10.79, p<0.05],[F(1.4)=16.94$, $\mathrm{p}<0.05][F(1.4)=157.39, \mathrm{p}<0.05]$, and $[\mathrm{F}(1.4)=184.72, \mathrm{p}<0.05]$, respectively. These results were obtained using Fisher's test, which evaluates the intra- and inter-group study variance.

Diethyl ether and petroleum ether extractions resulted in similar recoveries, with no significant differences between them. Lower standard deviations and associated errors are observed with diethyl ether, which makes diethyl ether the most promising option ( Fig. 1).

Another relevant parameter, also studied, was the sonication time (5-30 min) that might result in a greater recovery of the target analytes, as well as influence signal intensity. All studied times of extraction resulted in similar recoveries, with no significant differences between them. The sonication appears not to depend on the time of exposure to the solvent mixture. In order to make the process faster, 5 min was chosen.

The data were used to develop an optimized sample preparation protocol using $10 \mu \mathrm{L}$ of cannabis oil with $10 \mathrm{~mL}$ of diethyl ether, with sonication for $5 \mathrm{~min}$ and vortexing for $30 \mathrm{sec}$ ( 3 cycle sonication/vortexing).

Full method validation was conducted according to the FDA and $\mathrm{ICH}$ guidelines using olive and cannabis oil as matrix. The selectiv- 


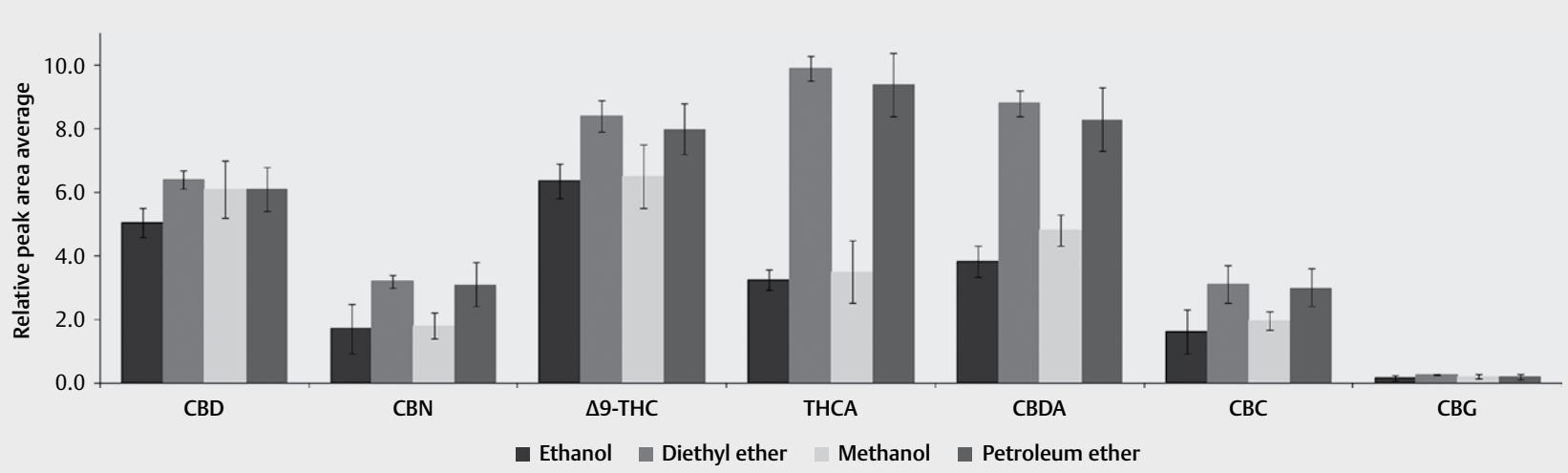

- Fig. 1 Relative peak areas and SDs obtained for different dilution solvents for cannabidiol (CBD), cannabinol (CBN), $\Delta^{9}$-tetrahydrocannabinol $\left(\triangle^{9}-\mathrm{THC}\right)$, tetrahydrocannabinolic acid (THCA), cannabidiolic acid (CBDA), cannabichromene (CBC) and cannabigerol (CBG).

ity of the method was evaluated by analyzing of blank samples. No interfering substances were detected at the selected retention times and $\mathrm{m} / \mathrm{z}$ windows for all cannabinoids. Using the above-mentioned criteria for positivity, all the analytes ( $\triangle^{9}-T H C, C B D$, and $\left.C B N\right)$ were successfully and unequivocally identified in all the spiked samples at the LLOQ. Therefore, the method was considered selective for $\Delta^{9}$-THC, CBD, and CBN determination.

The calibration model was evaluated from a set of 9 calibration points. The homoscedasticity assumption was tested in a linear regression analysis. The residual plot clearly showed that error was not randomly distributed around the concentration axis. The F-test also revealed a significant difference between the variances. There was evidence that variances were significantly different, thus homoscedasticity was not met.

Weighted least squares regressions had to be adopted in order to compensate for heteroscedasticity. Six weighting factors were evaluated for each compound $\left(1 / x^{0.5}, 1 / x, 1 / x^{2}, 1 / y^{0.5}, 1 / y, 1 / y^{2}\right)$. The weighting factor that resulted in the lower sum of relative errors and, simultaneously, a mean $\mathrm{R}^{2}$ value of at least 0.99 was chosen. This factor was $1 / x^{2}$ for all analytes. The method obtained linear relationships by means of these weighted least squares regressions. Calibrators' accuracy [mean relative error (bias) between the measured and spiked concentrations] was within a $\pm 15 \%$ interval for all concentrations. Calibration data are shown in $>$ Table 1.

The LLOQs of the compounds were $0.1 \mu \mathrm{g} / \mathrm{mL}$ for $\Delta^{9}$-THC, CBD; and $0.04 \mu \mathrm{g} / \mathrm{mL}$ for CBN ( $>$ Table 1), and the upper limit of quantification ranged from 11.7 (CBD) to $30.0\left(\Delta^{9}-\mathrm{THC}, \mathrm{CBD}\right) \mu \mathrm{g} / \mathrm{mL}$ with a minimum of 9 calibration points.

These limits were considered satisfactory, especially when compared to those obtained by other authors. Citti et al. [36] used $100 \mu \mathrm{L}$ (10 times higher) of cannabis oil, and the reported LLOQs for $\triangle^{9}$-THC, CBD, and CBN were greater than that presented herein. Bettiol et al. [37] and Deida et al. [38] applied $40 \mu \mathrm{L}$ (4 times higher) of cannabis oil and reported LLOQs of $1.0 \mu \mathrm{g} / \mathrm{mL}$ for $\Delta^{9}-\mathrm{THC}$, $\mathrm{CBD}$, and CBN. The mentioned papers report higher LLOQs than ours when analyses were carried out using a LC-DAD or LC-MS system. A GC-MS analytical method reported by Ciolino et al. [23] presented a LLOQs of $0.3 \mu \mathrm{g} / \mathrm{mL}$ for $\Delta^{9}-\mathrm{THC}, \mathrm{CBD}$, and CBN; how- ever, this work, unlike ours, started from gravimetrically measured samples.

Both intra-day and inter-day precisions for the entire extraction and analysis process were determined by extracting 2 cannabis oils over the course of 5 days, and 5 times on a single day. These oils were chosen to obtain a broad representation of analyte profiles. Cannabis oil A contains a high concentration of CBD and a low concentration of $\Delta^{9}$-THC and CBN, while cannabis oil B contains a low concentration of CBD and a high concentration of $\Delta^{9}-\mathrm{THC}$ and CBN.

Intra-day precision was evaluated by analyzing, on the same day, 5 replicates of the cannabis oils. The obtained \% RSD were lower than $13.8 \%$ at all studied concentration levels. ( $>$ Table 2 ). The evaluation of inter-day precision was made within a 5-day period. The obtained \% RSD were lower than $14.1 \%$ for all cannabinoids at the tested concentrations. ( $\triangleright$ Table $\mathbf{2}$ ).

The recovery was evaluated at LLOQ for $\Delta^{9}-\mathrm{THC}, \mathrm{CBD}$, and CBN. The recoveries for the compounds were between $95 \%$ and $103 \%$ ( $\triangleright$ Table 1). According to our results, the method can be considered a powerful technique, revealing a fast and efficient extraction of the target analytes with a lower sample volume.

After validation of this analytical method, in order to demonstrate the applicability, it was successfully applied to routine analysis of 10 cannabis oils.

In controlled/regulated production cannabis oils (cannabis oil \#1 and \#2), CBD was detected at levels consistent with the product labeling, and $\Delta^{9}$-THC levels were very low, as expected for products derived from hemp oil ( $\triangleright$ Table 3 ). In addition, cannabis oil \#1 and \#2 showed high ratios of CBD to $\triangle^{9}$-THC and CBN ( $\triangleright$ Table 3 ).

Uncontrolled/unregulated production cannabis oils had CBD, $\Delta^{9}$-THC, and CBN concentrations that differed notably. Our analysis revealed that 2 preparations (samples oils \#3 and \#7) exhibited high levels of $\Delta^{9}$-THC and low or undetectable concentration of CBD, while in another 3 (samples oil \#6, \#8, and \#9), the CBD content was not detectable and $\Delta^{9}-\mathrm{THC}$ ranged from 1.3 to $4.3 \mathrm{mg} / \mathrm{mL}$ ( Table 3).

CBD appears not to have adverse consequences at high doses; however, $\Delta^{9}$-THC concentrations observed in cannabis oils (especially oil \# 3, \# 4, \# 7, \# 8) could be enough to produce intoxication, especially among children [39]. 


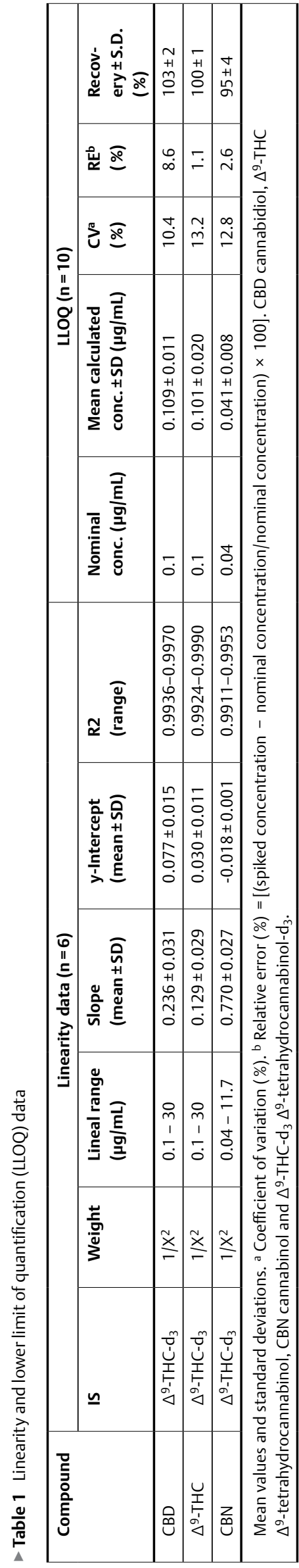

Interestingly, the web site from the CBD oil \#4 producer reports a $\mathrm{CBD} / \Delta^{9}-\mathrm{THC}$ ratio of $1: 1$, while we found a $\mathrm{CBD} / \Delta^{9}-\mathrm{THC}$ ratio of 0.25:1.

Finally, in the cannabis oil \#10, CBD, $\Delta^{9}-T H C$, and CBN were not detected, which would indicate that it was falsely sold as cannabis oil.

CBN was quantifiable in most samples (except oil \#5, \#8, and $\# 10$ ). $C B N$ is formed by $\Delta^{9}-T H C$ oxidation during plant aging or inappropriate storage conditions [40]. Therefore, its determination may assist in the evaluation of the quality of cannabis oils.

Taken together, the results highlighted the extreme variability of the uncontrolled/unregulated production of cannabis oils, and these results are in agreement with those obtained from products available on the United States and Italy markets [41, 42]. BonnMiller et al. [41] reported that $26 \%$ of tested products contained less CBD than declared on the label, while Pavlovich et al. [42] reported 9 out of 14 tested samples had concentrations that differed notably from the declared amount.

In conclusion, a GC-MS method was developed, optimized, validated, and applied for the simultaneous detection and quantification of CBD, $\Delta^{9}-\mathrm{THC}$, and CBN in cannabis oil. The analyses were carried out using small sample volumes ( $10 \mu \mathrm{L}$ of cannabis oil), and the method was successfully applied to real samples derived from Argentina's market.

The issues of variability of cannabinoid content in preparations and inaccurate label claims in the global market justify the need to have a method like the one that has been developed and validated to provide concentration data for each preparation.

To our knowledge, this is the first method available in Argentina validated according to international guidelines for quantification of CBD, $\triangle^{9}$-THC, and CBN in cannabis oil.

In addition, $\mathrm{CBD}$ and $\Delta^{9}$-THC concentration data in medicinal cannabis oil are crucial for physicians to be able to properly adapt the prescribed dose to the available preparation.

Further studies are needed to evaluate the impact of different cannabis oils on cannabinoids pharmacokinetics and clinical outcomes.

\section{Materials and Methods}

\section{Reagents and standards}

Analytical standards: $\Delta^{9}$-THC (purity $99.4 \%$ ), CBD (purity $99.8 \%$ ), CBN (purity 99.5\%), and ISTD: $\Delta^{9}$-tetrahydrocannabinol-d ${ }_{3}\left(\Delta^{9}-\mathrm{THC}\right.$ $-d_{3}$, purity $98.8 \%$ ) were purchased from Cerilliant (Round Rock, TX, USA) as 1.0 and $0.1 \mathrm{mg} / \mathrm{mL}$ in methanol solutions.

Methanol, ethanol, diethyl ether, petroleum ether, and ethyl acetate were provided from Merck Chemistry (Buenos Aires, Argentina); all chemicals were analytical ACS or chromatography grade. MSTFA was acquired from Thermo Fisher Scientific.

\section{Calibrators and internal standard}

A working solution (A) was prepared by proper dilution of stock solutions $(1 \mathrm{mg} / \mathrm{mL})$ with methanol to the final concentrations of 10.0 $\mu \mathrm{g} / \mathrm{mL}$ for $\Delta^{9}$-THC and CBD. Additionally, working solutions of 400 and $4.0 \mu \mathrm{g} / \mathrm{mL}$ for CBN were prepared. As ISTD $\left(\Delta^{9}-\mathrm{THC}-\mathrm{d}_{3}\right)$ stock 
- Table 2 Intra-day and inter-day precision data.

\begin{tabular}{|c|c|c|c|c|c|}
\hline \multirow[t]{2}{*}{ Cannabis Oil } & \multirow[t]{2}{*}{ Compound } & \multirow{2}{*}{$\begin{array}{l}\text { Intra-day }(\mathrm{n}=5) \\
\text { Measured } \pm S D(\mu \mathrm{g} / \mathrm{mL})\end{array}$} & \multicolumn{3}{|c|}{ Inter-day $(n=15)$} \\
\hline & & & $\operatorname{RSD}^{\mathrm{a}}(\%)$ & Measured $\pm S D(\mu \mathrm{g} / \mathrm{mL})$ & $\operatorname{RSD}^{\mathrm{a}}(\%)$ \\
\hline \multirow[t]{3}{*}{ A } & CBD & $23.60 \pm 0.81$ & 4.5 & $22.45 \pm 0.71$ & 4.7 \\
\hline & $\Delta^{9}-\mathrm{THC}$ & $0.42 \pm 0.09$ & 3.9 & $0.52 \pm 0.10$ & 10.7 \\
\hline & CBN & $0.18 \pm 0.04$ & 13.8 & $0.17 \pm 0.04$ & 12.5 \\
\hline \multirow[t]{3}{*}{ B } & CBD & $0.11 \pm 0.04$ & 11.3 & $0.10 \pm 0.06$ & 11.7 \\
\hline & $\Delta^{9}-\mathrm{THC}$ & $28.20 \pm 2.51$ & 10.3 & $25.81 \pm 3.74$ & 10.9 \\
\hline & CBN & $4.81 \pm 0.43$ & 12.9 & $4.27 \pm 0.61$ & 14.1 \\
\hline
\end{tabular}

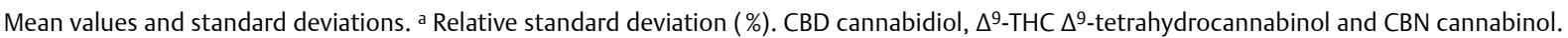

- Table 3 Cannabinoid content of tested authentic samples.

\begin{tabular}{|c|c|c|c|c|c|}
\hline $\begin{array}{l}\text { Canna- } \\
\text { bis Oil }\end{array}$ & $\begin{array}{l}\text { Declared } \\
\text { CBD }^{*}(\mathrm{mg} / \mathrm{mL})\end{array}$ & $\begin{array}{l}\text { CBD } \\
(\mathrm{mg} / \\
\mathrm{mL})\end{array}$ & $\begin{array}{l}\Delta^{9} \text {-THC } \\
(\mathrm{mg} / \\
\mathrm{mL})\end{array}$ & $\begin{array}{l}\text { CBN } \\
(\mathrm{mg} / \\
\mathrm{mL})\end{array}$ & $\begin{array}{l}\text { CBD / } \\
\Delta^{9} \text {-THC } \\
\text { ratio }\end{array}$ \\
\hline \# 1 & 20 & 22.0 & 1.1 & 1.1 & 20 \\
\hline$\# 2$ & 20 & 22.0 & 1.0 & 1.0 & 22 \\
\hline \# 3 & Not declared & 0.4 & 29.0 & 3.4 & 0.01 \\
\hline$\# 4$ & Not declared & 1.5 & 6.1 & 0.3 & 0.25 \\
\hline$\# 5$ & Not declared & 0.3 & 2.0 & ND & 0.15 \\
\hline$\# 6$ & Not declared & ND & 1.3 & 0.6 & - \\
\hline \# 7 & Not declared & ND & 10.3 & 2.6 & - \\
\hline$\# 8$ & Not declared & ND & 4.3 & ND & - \\
\hline$\# 9$ & Not declared & ND & 2.4 & 0.2 & - \\
\hline \# 10 & Not declared & ND & ND & ND & - \\
\hline
\end{tabular}

solutions of $0.1 \mathrm{mg} / \mathrm{mL}$ was used. All primary and working solutions were stored at $-20^{\circ} \mathrm{C}$ into amber glass vials.

Working calibrators $(0.1,2.0,4.0,6.0,8.0,10.0,15.0,20.0$, and $30.0 \mu \mathrm{g} / \mathrm{mL} \Delta^{9}$-THC and CBD; and 0.04, 0.80, 1.50, 2.40, 3.20, 3.90, $5.90,7.80$, and $11.70 \mu \mathrm{g} / \mathrm{mL}$ CBN) were made daily by adding of each standard to $1.0 \mathrm{~mL}$ (final volume) of ethanol. For the $0.1 \mu \mathrm{g} / \mathrm{mL} \Delta^{9}$ THC and CBD and $0.04 \mu \mathrm{g} / \mathrm{mL} C B N$ points, working solution $(A)$ and $4.0 \mu \mathrm{g} / \mathrm{mL} C B N$ were used, respectively. For the rest of the points, stock solutions and a working solution of $400 \mu \mathrm{g} / \mathrm{mL}$ CBN, were used.

\section{Tested material}

The cannabis oil extracts used in this study were obtained from subjects who attended the Analytical Toxicology Advisory Laboratory (CENATOXA) with a request for quantification of $\Delta^{9}$-THC and CBD.

Eight samples were obtained from uncontrolled/unregulated production cannabis oil ( $n=8)$ and 2 samples from controlled/regulated production cannabis oil $(n=2)$.

\section{Gas chromatography and mass spectrometry analysis}

The samples were analyzed using an HP $6890 \mathrm{~N}$ gas chromatograph, combined with an HP 5973 quadrupole mass spectrometer and an HP 6890 Series injector (all from Hewlett-Packard). Data were acquired and analyzed using Agilent Enhanced ChemStation G1701DA software (Agilent Technologies). The separation of the analytes was achieved using a capillary column $(30 \mathrm{~m} \times 0.25 \mathrm{~mm}$ I.D., $0.25 \mu \mathrm{m}$ film thickness) with $5 \%$ phenylmethylsiloxane (HP-5 MS), supplied by J \& W Scientific. Carrier gas (helium) was set at a constant flow rate of $1.0 \mathrm{~mL} / \mathrm{min}$. The volume of injection was $2 \mu \mathrm{L}$ on split mode (split ratio of $1: 10$ ); the injection port and transfer line temperatures were set at $280^{\circ} \mathrm{C}$ and $280^{\circ} \mathrm{C}$, respectively. The oven temperature started at $60^{\circ} \mathrm{C}$, followed by a temperature ramp of $10^{\circ} \mathrm{C} / \mathrm{min}$ to $300^{\circ} \mathrm{C}$ held for $2 \mathrm{~min}$. Total separation run time was $26.0 \mathrm{~min}$. The ion source was maintained at $220^{\circ} \mathrm{C}$ and the quadrupole at $150{ }^{\circ} \mathrm{C}$. The mass spectrometer was operated with a filament current of $300 \mathrm{~mA}$ and an electron energy of $70 \mathrm{eV}$ in the positive electron ionization mode. Selected ion monitoring mode was used with a dwell time of 80 ms. Three ions for each analyte and 1 ion for ISTD were chosen based on selectivity and abundance in order to maximize the signal-to-noise ratio in matrix extracts ( $\triangleright$ Table 4). Agilent Enhanced ChemStation G1701DA software (Agilent Technologies) was used for data acquisition, data processing, and instrument control. The mass spectra were obtained by collecting the data at rate of $1.38 \mathrm{scan} / \mathrm{s}$ over the $\mathrm{m} / \mathrm{z}$ range of 50 600 . Compounds were identified by comparing the retention times of the chromatographic peaks with those of authentic compounds analyzed under the same conditions when available and through the National Institute of Standards and Technology (NIST 1998); Pfleger/Maurer/Weber: Mass Spectral Library of Drugs, Poisons, Pesticides, Pollutants and Their Metabolites (2011), and Scientific Working Group for the Analysis of Seized Drugs (SWGDRUG 2019), MS spectral database.

\section{Sample preparation}

Cannabis oil was mixed by inversion prior to sample preparation. Then $10 \mu \mathrm{L}$ of oil was diluted thousand-fold (1:1000 dilution) in 10 $\mathrm{mL}$ of diethyl ether and vortexed for $30 \mathrm{sec}$. Extracts were sonicated for $5 \mathrm{~min}$ and vortexed for $30 \mathrm{sec}$. The sonication and agitation cycles were performed twice more.

One hundred microliters $(100 \mu \mathrm{L})$ of extract with $4 \mu \mathrm{L}$ of ISTD $(0.1 \mathrm{mg} / \mathrm{mL})$ were evaporated to dryness under a gentle stream of nitrogen at $45^{\circ} \mathrm{C}$. For the derivatization procedure, $50 \mu \mathrm{L}$ of MSTFA were added to the dried residue and vortexed for $10 \mathrm{sec}$. The tubes were heated on a thermo block at $60^{\circ} \mathrm{C}$ for $20 \mathrm{~min}$. A $2 \mu \mathrm{L}$ aliquot of the resulting solution was injected into the GC-MS system. 
- Table 4 Optimized identification parameters for compounds

\begin{tabular}{|c|c|c|c|c|c|c|c|}
\hline Compound & $\begin{array}{l}\text { Retention } \\
\text { Time (min) }\end{array}$ & $\begin{array}{l}\text { Time window } \\
\text { (min) }\end{array}$ & $\begin{array}{l}\text { Quantification } \\
\text { ion }(m / z)\end{array}$ & $\begin{array}{l}\text { Qualifier ion } \\
1(\mathrm{~m} / \mathrm{z})\end{array}$ & $\begin{array}{l}\text { Qualifier ion } \\
2(\mathrm{~m} / \mathrm{z})\end{array}$ & $\begin{array}{l}\text { Dwell time } \\
\text { (ms) }\end{array}$ & $\begin{array}{l}\text { Peak width } \\
\text { (m/z units) }\end{array}$ \\
\hline CBD & 20.944 & $20.50-21.30$ & 390 & 337 & 458 & 80 & 0.5 \\
\hline$\triangle^{9}-\mathrm{THC}$ & 21.807 & $21.30-22.10$ & 371 & 315 & 386 & 80 & 0.5 \\
\hline$\Delta^{9}-\mathrm{THC}-\mathrm{d}_{3}$ & 21.787 & $21.30-22.10$ & 374 & - & - & 80 & 0.5 \\
\hline CBN & 22.564 & $22.10-22.90$ & 367 & 238 & 310 & 80 & 0.5 \\
\hline
\end{tabular}

CBD cannabidiol, $\Delta^{9}$-THC $\Delta^{9}$-tetrahydrocannabinol, $\Delta^{9}$-THC- $\mathrm{d}_{3} \Delta^{9}$-tetrahydrocannabinol- $\mathrm{d}_{3}$ and CBN cannabinol.

\section{Validation procedure}

The analytical method validation was performed in accordance with the guidelines of the FDA [30] and ICH [31]. The validation was performed following a 5-day validation protocol and included selectivity/specificity, linearity, limits, intra- and inter-day precision, and recovery.

\section{Selectivity}

Since it is not possible to obtain cannabis oil that is devoid of cannabinoids, blank samples were prepared using olive oil ( $n=10)$. Samples were extracted and analyzed according to the previously described procedure.

Peaks at the retention time of interest were compared with those from olive oil samples spiked with analytes at the LLOQ.

The acceptance criteria for compounds identification were according to the WADA [34]. The method would be considered selective if no analyte could be identified in the blank samples by applying those criteria.

\section{Calibration curves and limits}

The linearity of the method was established on aliquots of ethanol $(100 \mu \mathrm{L})$ spiked with the corresponding working solution to obtain calibrator samples. Replicates $(n=9)$ at each concentration were analyzed as described Fernandez et al. [35].

The lowest point of the calibration curve was the LLOQ of the method. The LLOQ was determined by analyzing 10 replicates of spiked blank olive oil samples (independent from those of the calibration curve). It was tested whether the signal-to-noise ratios $(\mathrm{S} / \mathrm{N})$ of all analytes was greater than 10 . Furthermore, precision and accuracy data with a coefficient of variation (CV\%) less than $20 \%$ and a relative error (RE \%) within $\pm 20 \%$ of the nominal concentration were obtained.

\section{Intra- and inter-day precision}

In order to evaluate intra- and inter-day precision, different authentic samples containing different cannabinoid profiles were evaluated on 5 separate days as well as 5 times on the same day.

Precision, expressed as \% RSD, was determined by calculating the percent ratio of the standard deviation divided by the calculated mean concentration times 100. Data were evaluated using a 1 -way analysis of variance (ANOVA) with day as the grouping variable. RSD values below $15 \%$ and at LLOQ below $20 \%$ were acceptable for quantitative analysis.

\section{Recovery}

For the analysis of recovery, 2 sets of samples $(n=5)$ were prepared at LLOQ: sample set 1 representing the neat standard/ISTD and sample set 2 consisting of blank olive oil spiked before dilution. The ISTD were added to sample set 2 after dilution. The recovery results were obtained by comparison of peak areas ratio of sample set 1 to those of the corresponding peaks in sample set 2 .

\section{Conflicts of Interest}

The authors declare that they have no conflicts of interest.

\section{References}

[1] Gonçalves ], Rosado T, Soares S, Simão AY, Caramelo D, Luís Â, Fernández N, Barroso M, Gallardo E, Duarte AP. Cannabis and its secondary metabolites: their use as therapeutic drugs, toxicological aspects, and analytical determination. Medicines 2019; 6: 31

[2] Garb S. Cannabinoids in the management of severe nausea and vomiting from cancer chemotherapy. Some additional considerations. J Clin Pharmacol 1981; 21: 57S-59S

[3] Lewis DY, Brett RR. Activity-based anorexia in C57/BL6 mice: Effects of the phytocannabinoid, 9-tetrahydrocannabinol (THC), and the anandamide analog, OMDM-2. Eur Neuropsychopharmacol 2010; 20: 622-631

[4] De Lago E, Gomez-Ruiz M, Moreno-Martet M, Fernandez-Ruiz ]. Cannabinoids, multiple sclerosis, and neuroprotection. Exp Rev Clin Pharmacol 2009; 2: 645-660

[5] Maurer M, Henn V, Dittrich A, Hofmann A. 9-tetrahydrocannabinol shows antispastic and analgesic effects in a single case double-blind trial. Eur Arch Psychiatr Clin Neurosci 1990; 240: 1-4

[6] Flores-Sanchez IJ, Verpoorte R. Secondary metabolism in cannabis. Phytochem Rev 2008; 7: 615-639

[7] Rong C, Lee Y, Carmona NE, Cha DS, Ragguett RM, Rosenblat JD, Mansur RB, Ho RC, Mclntyre RS. Cannabidiol in medical marijuana: Research vistas and potential opportunities. Pharmacol Res 2017; 121 : 213-218

[8] Russo EB. Cannabinoids in the management of difficult to treat pain. Ther Clin Risk Manag 2008; 4: 245-459

[9] Whiting PF, Wolff RF, Deshpande S, Di Nisio M, Duffy S, Hernandez AV, Keurentjes JC, Lang S, Misso K, Ryder S, Schmidlkofer S, Westwood M, Kleijnen J. Cannabinoids for medical use: a systematic review and meta-analysis. JAMA 2015; 313: 2456-2473

[10] Borgelt LM, Franson KL, Nussbaum AM, Wang GS. The pharmacologic and clinical effects of medical cannabis. Pharmacotherapy 2013; 33: 195-209 
[11] Pisanti S, Malfitano AM, Ciaglia E, Lamberti A, Ranieri R, Cuomo G, Abate M, Faggiana G, Proto MC, Fiore D, Laezza C, Bifulco M. Cannabidiol: state of the art and new challenges for therapeutic applications. Pharmacol Ther 2017; 175: 133-150

[12] Lercker G, Bocci F, Frega N, Bortolomeazzi R. Cannabinoid acids analysis. Farmaco 1992; 47: 367-378

[13] Perrotin-Brunel H, Buijs W, van Spronsen J, van Roosmalen MJE, Peters C], Verpoorte R, Witkamp GJ. Decarboxylation of $\Delta 9$ tetrahydrocannabinol: kinetics and molecular modelling. J Mol Struct 2011; 987: 67-73

[14] Politi M, Peschel W, Wilson N, Zloh M, Prieto JM, Heinrich M. Direct NMR analysis of cannabis water extracts and tinctures and semi-quantitative data on $\triangle 9$-THC and $\triangle 9$-THC-acid. Phytochemistry 2008; 69: 562-570

[15] Veress T, Szanto JI, Leisztner L. Determination of cannabinoid acids by high-performance liquid chromatography of their neutral derivatives formed by thermal decarboxylation: I. Study of the decarboxylation process in open reactors. J Chromatogr A 1990; 520: 339-347

[16] Hazekamp A, Bastola K, Rashidi H, Bender J, Verpoorte R. Cannabis tea revisited: a systematic evaluation of the cannabinoid composition of cannabis tea. J Ethnopharm 2007; 113: 85-90

[17] Fischedick JT, Hazekamp A, Erkelens T, Choi YH, Verpoorte R. Metabolic fingerprinting of cannabis sativa L., cannabinoids and terpenoids for chemotaxonomic and drug standardization purposes. Phytochem 2010; 71: 2058-2073

[18] US Food and Drug Administration (FDA). Warning letters and test results for cannabidiol-related products. Available at: https://www.fda. gov/news-events/public-health-focus/warning-letters-and-testresults-cannabidiol-related-products; Accessed March 03, 2020

[19] Ley 17818 De estupefacientes. Available at: http://www.anmat.gov.ar/ webanmat/Legislacion/Medicamentos/ley17818.pdf; Accessed July 22, 2019

[20] Ley 27350 Investigación médica y científica de uso medicinal de la planta de Cannabis y sus derivados. Available at: http://servicios. infoleg.gob.ar/infolegInternet/anexos/270000-74999/273801/norma. htm; Accessed July 22, 2019

[21] Pellegrini M, Marchei E, Pacifici R, Pichini S. A rapid and simple procedure for the determination of cannabinoids in hemp food products by gas chromatography-mass spectrometry. J Pharm Biomed Anal 2005; 36: 939-946

[22] Nahar L, Guo M, Sarker SD. Gas chromatographic analysis of naturally occurring cannabinoids: a review of literature published during the past decade. Phytochem Anal 2019; 1-12

[23] Ciolino LA, Ranieri TL, Taylor AM. Commercial cannabis consumer products part 1 : GC-MS qualitative analysis of cannabis cannabinoids. Forensic Sci Int 2018; 289: 429-437

[24] Citti C, Braghiroli D, Vandelli MA, Cannazza G. Pharmaceutical and biomedical analysis of cannabinoids: a critical review. J Pharm Biomed Anal 2018; 147: 565-579

[25] Meng Q, Buchanan B, Zuccolo J, Poulin M, Gabriele J, Baranowski DC. A reliable and validated LC-MS/MS method for the simultaneous quantification of 4 cannabinoids in 40 consumer products. PLoS One 2018; 13: e0196396

[26] Pacifici R, Marchei E, Salvatore F, Guandalini L, Busardò FP, Pichini S. Evaluation of long-term stability of cannabinoids in standardized preparations of cannabis flowering tops and cannabis oil by ultra-highperformance liquid chromatography tandem mass spectrometry. Clin Chem Lab Med 2018; 56: e94-e96
[27] Davis TWM, Farmilo CG, Osadchuk W. Identification and origin determinations of Cannabis by gas and paper chromatography. Anal Chem 1963; 35: 751-754

[28] Fetterman PS, Doorenbos N], Keith ES, Quimby MW. A simple gas liquid chromatography procedure for determination of cannabidiolic acids in Cannabis sativa L. Experientia 1971; 27: 988-990

[29] Parker JM, Stembal BL. Review of gas-liquid chromatography of marihuana. Journal of the AOAC 1974; 57: 888-892

[30] Food and Drug Administration (FDA) Bioanalytical Method Validation. Guidance for Industry. U.S. Department of Health and Human Services, Food and Drug Administration, FDA; 2018

[31] International Conference on Harmonization (ICH) Guidance for Industry, Q2B Validation of Analytical Procedures: Methodology. 1996

[32] Mudge EM, Murch S], Brown PN. Leaner and greener analysis of cannabinoids. Anal Bioanal Chem 2017; 409: 3153-3163

[33] Rutha AC, Gryniewicz-Ruzickaa CM, Trehya ML, Kornspanb N, Coodyb G. Consistency of label claims of internet-purchased hemp oil and cannabis products as determined using IMS and LC-MS: A marketplace survey. Journal of Regulatory Science 2016; 03: 1-6

[34] Word Anti-Doping Agency (WADA) Minimum criteria for chromatographic-mass spectrometric confirmation of the identity of analytes for doping control purposes. 2015

[35] Fernández N, Cabanillas LM, Olivera NM, Quiroga PN. Optimization and validation of simultaneous analyses of ecgonine, cocaine, and 7 metabolites in human urine by gas chromatography-mass spectrometry using a one-step solid-phase extraction. Drug Test Anal 2019; 11: 361-373

[36] Citti C, Pacchetti B, Vandelli MA, Forni F, Cannazza G. Analysis of cannabinoids in commercial hemp seed oil and decarboxylation kinetics studies of cannabidiolic acid (CBDA). J Pharm Biomed Anal 2018; 49: 532-540

[37] Bettiol A, Lombardi N, Crescioli G, Maggini V, Gallo E, Mugelli A, Firenzuoli F, Baronti R, Vannacci A. Galenic preparations of therapeutic cannabis sativa differ in cannabinoids concentration: A quantitative analysis of variability and possible clinical implications. Front Pharmacol 2019; 9: 1543

[38] Deiddaa R, Avohou HT, Baronti R, Davolioc PL, Pasquini B, Del Bubba M, Huberta C, Huberta P, Orlandinid S, Furlanetto S. Analytical quality by design: Development and control strategy for a LC method to evaluate the cannabinoids content in cannabis olive oil extracts. J Pharm Biomed Anal 2019; 166: 326-335

[39] Crippa JA, Crippa AC, Hallak JE, Martín-Santos R, Zuardi AW. $\triangle$ 9-THC Intoxication by cannabidiol-enriched cannabis extract in two children with refractory epilepsy: Full remission after switching to purified cannabidiol. Front Pharmacol 2016; 7: 359

[40] Ross SA. ElSohly MACBN and D9-THC concentration ratio as an indicator of the age of stored marijuana samples. Bull Narc. 1997; 49: 139-147

[41] Bonn-Miller MO, Loflin MJ, Thomas BF, Marcu JP, Hyke T, Vandrey R. Labeling accuracy of cannabidiol extracts sold online. JAMA 2017; 318 : 1708-1709

[42] Pavlovic R, Nenna G, Calvi L, Panseri S, Borgonovo G, Giupponi L, Cannazza G, Giorgi A. Quality traits of "cannabidiol oils": Cannabinoids content, terpene fingerprint and oxidation stability of European commercially available preparations. Molecules 2018; 23: 1230 